This document is the Accepted Manuscript version of the following article: Kupeli, N., Norton, S., Chilcot, J. et al, 'A Confirmatory Factor Analysis and Validation of the Vulnerable Attachment Style Questionnaire', Journal of Psychopathology and Behavioral Assessment, Vol. 37(1): 153-163, first published online 24 May 2014.

The final publication is available at Springer via http://dx.doi.org/ 10.1007/s10862-014-9432-3 
Cite as:

Kupeli, N., Norton, S., Chilcot, J., Schmidt, U., Campbell, I. C. \& Troop, N. (2015). A

Confirmatory Factor Analysis and Validation of the Vulnerable Attachment Style

Questionnaire. Journal of Psychopathology and Behavioral Assessment, 37(1), 153-163.

\section{A Confirmatory Factor Analysis and Validation of the Vulnerable Attachment Style Questionnaire}

Nuriye Kupeli*1, Sam Norton ${ }^{2}$, Joseph Chilcot ${ }^{2}$, Ulrike H. Schmidt ${ }^{2}$, lain C. Campbell ${ }^{2}$ \& Nicholas A. Troop ${ }^{3}$

${ }^{1}$ Marie Curie Palliative Care Research Unit, University College London, UK

2 Institute of Psychiatry, King's College London, UK

${ }^{3}$ School of Psychology, University of Hertfordshire, UK

* Requests for correspondence should be addressed to: Nuriye Kupeli, Marie Curie Palliative Care Research Unit, Division of Psychiatry, University College London, 67-73

Charles Bell House, Riding House Street, London, W1W 7EJ, U.K (Email:

N.Kupeli@ucl.ac.uk; Tel: 0207679 9724)

\section{Acknowledgments}

The authors are grateful to Professor Antonia Bifulco for her helpful comments on an earlier draft of this paper. This research was supported by a Medical Research CouncilEconomic and Social Research Council (MRC-ESRC) interdisciplinary award. 


\begin{abstract}
Objective: The Vulnerable Attachment Style Questionnaire (VASQ; Bifulco, Mahon, Kwon, Moran \& Jacobs, 2003) was developed to assess adult attachment as a vulnerability factor for developing depression and identified two subscales, insecure attachment and proximity-seeking. The present study sought to confirm and further validate the factor structure of the VASQ in a large community convenience sample. Method: The VASQ was completed by a large sample of men and women $(N=1236)$ as part of an online survey. The data were randomly split to allow both independent exploratory (EFA) and confirmatory factor analyses (CFA) to be conducted.

Results: A four-factor model consisting of two types of proximity-seeking (lack of autonomy and anxious-dependent) and insecurity (ambivalent and avoidant-dismissive) attachment patterns proved to be the best-fitting measurement model in this sample $\left(X^{2}=186.7, \mathrm{df}=71, p<.001 ; \mathrm{CFI}=.945, \mathrm{TLI}=.929, \mathrm{RMSEA}=.05\right)$. Although similar to the original questionnaire, the new factor structure resulted in the elimination of several items. Validity was confirmed with the shortened VASQ as similar associations with mood, stress, eating pathology and sex were observed for both the new shortened VASQ and original version of the VASQ.

Conclusions: The structure of the VASQ was broadly consistent with the original solution although some items were removed and both subscales were further split into two subfactors. Future research should use this tool in clinical and non-clinical groups to provide further support for its factor structure and to determine the clinical and theoretical usefulness of the different subscales.
\end{abstract}




\section{Keywords}

Attachment

Vulnerable Attachment Style Questionnaire (VASQ)

Confirmatory Factor Analysis (CFA)

Disordered eating

Mood

Stress 


\section{Introduction}

Attachment refers to the bond that develops between an infant and its caregiver to provide young children not only with a sense of security and to aid survival but to develop patterns of emotion regulation (Bowlby, 1977). Following observations of caregiver-infant interactions, Ainsworth, Blehar, Waters and Wall (1978) formulated the three types of attachment styles known as secure, anxious/ambivalent and avoidant, with the latter two referring to insecure attachment styles. The attachment between an infant and its caregiver can persist and even shape later affectional bonds formed during adulthood (Ainsworth, 1985). Hazan and Shaver's (1987) research suggests that the infant-caregiver attachment bond described by Ainsworth (1985) provides a plausible framework for understanding attachments formed in adulthood. Secure attachment patterns in adulthood characterise adults who are comfortable with getting close to and depending on others. However, those with an avoidant attachment style have difficulty trusting others and are uncomfortable with intimacy. Anxious/ambivalent adults worry that others do not really care about them and are often characterised as being highly dependent on others.

The theoretical foundations of attachment theory (Ainsworth et al., 1978; Bowlby, 1977) have been used to develop measures to assess patterns of attachment behavior in adulthood (see reviews: Crowell \& Treboux, 1995; Lyddon, Bradford \& Nelson, 1993; Ravitz, Maunder, Hunter, Sthankiya \& Lancee, 2010). These include both interview-based and self-report assessments. Research demonstrates that securely attached individuals (as opposed to insecurely attached) develop the ability to self- 
soothe and regulate their emotions (Sloman, Gilbert \& Hasey, 2003). Therefore, measures assessing adult attachment styles have been used to evaluate the impact of adult attachments (specifically insecurity of attachment) on psychopathology including depression, anxiety, stress and eating disorders (e.g., Bifulco, Kwon, Jacobs, Moran, Bunn \& Beer, 2006; Ditzen, Schmidt, Strauss, Nater, Ehlert \& Heinrichs, 2008; Kidd, Hamer \& Steptoe, 2011; Mickelson, Kessler \& Shaver, 1997; Ward, Ramsay \& Treasure, 2000; Zachrisson \& Skårderud, 2010).

A review of adult attachment measures is beyond the scope of this report (for a full review see; Ravitz et al., 2010) but a brief summary of some of the key measures may be useful. The Adult Attachment Styles (AAS; Hazan \& Shaver, 1987) is a categorical measure consisting of three short descriptions of adult attachment attitudes. Collins and Read (1990) used the individual statements of the AAS (Hazan \& Shaver, 1987) to develop a continuous measure of adult attachment. Using factor analysis, these authors identified three types of attachment styles, trusting and depending on others (Depend dimension), relationship anxiety including fear of being abandoned (Anxiety dimension) and being comfortable with closeness and intimacy (Close dimension). Other measures of adult attachment styles include the Relationship Questionnaire (RQ; Bartholomew \& Horowitz, 1991) and the Experiences in Close Relationships questionnaire (ECR; Brennan, Clark \& Shaver, 1998). Although both of these measures assess secure, preoccupied, fearful and dismissing attachment styles, the ECR (Brennan et al., 1998) examines these four styles based on attachment-related anxiety and avoidance. 
While a number of authors have sought to develop measures of attachment that identify theoretically meaningful styles, Bilfulco, Mahon, Kwon, Moran and Jacobs (2003) argued that it is important to develop a measure which not only assesses the severity of vulnerable attachment in adulthood but one that can identify those at high risk for psychopathology such as depression. Based on the Attachment Style Interview (ASI; Bifulco, Moran, Ball \& Bernazzani, 2002a; Bifulco, Moran, Ball \& Lillie, 2002b) Bifulco et al. (2003) developed the Vulnerable Attachment Style Questionnaire (VASQ). This is a 22-item scale used to assess the degree of vulnerability to psychopathology due to attachment issues. Specifically two subscales were identified, labelled as 'Insecurity' and 'Proximity-seeking'. Insecurity was a stronger predictor of depression than was Proximity-seeking, although in some analyses the combined scores were stronger predictors of depression than either scale on its own (Bifulco et al., 2003). Other authors have also found that it is the Insecurity subscale rather than Proximity-seeking which is more strongly related to psychopathology. The Insecurity subscale is positively related to depressive symptoms, loneliness and detached mourning (an attitude that maintaining an emotional involvement with a close one who has died will hinder the mourning process) and negatively correlated with perceptions of competence, autonomy, relatedness and social support (Carr, Colthurst, Coyle \& Elliott, 2012; Sochos \& Bone, 2012).

Ravitz et al.'s (2010) systematic review of adult attachment measures suggests that the VASQ has good validity and reliability indicating that it is a promising measure and the authors recommend its further use and development. Its potential importance also 
stems from the fact that Bifulco et al. (2003) demonstrated that it is a better predictor of the subsequent onset of depression than another widely used measure of attachment styles, the RQ (Bartholomew \& Horowitz, 1991). Clearly, further psychometric evaluation of the VASQ is warranted as to date, the original study (Bifulco et al., 2003) is the only study which has examined the psychometric properties of the VASQ. In addition, the original development of the VASQ was based on a sample of middle-aged women and their family members (Bifulco et al., 2003), thus limiting its generalizability to the general population. Therefore, the aim of the current study was to examine the factor structure using exploratory and confirmatory factor analyses in a large and diverse sample. It was hypothesized that based on Bifulco et al.'s (2003) study, a two-factor solution consisting of Insecurity and Proximity-seeking would be found with the current data. However, as other measures of adult attachment styles reflect between two and four types of attachment patterns, the current study will also explore three and four factor solutions of the VASQ. For example, the ECR (Brennan et al., 1998) differentiates between anxious and avoidance attachment behaviours, whilst the AAS (Collins \& Read, 1990; Hazan \& Shaver, 1987) and the RQ (Bartholomew \& Horowitz, 1991) assess three and four types of adult attachment styles, respectively. There are many similarities between VASQ items and statements that have been used in these other measures to reflect different attachment patterns in adulthood. For example, the Insecurity scale of the VASQ includes items such as 'I find it hard to trust others' which correspond to 'I find it difficult to trust them' (Avoidant category; Hazan \& Shaver, 1987). Similarly, the Proximity-seeking component 
includes items such as 'I worry about things happening to close family and friends' which reflects 'I worry a lot about my relationships' (Anxiety category; Brennan et al., 1998).

In addition, the current study validated the VASQ in terms of its associations with mood, stress and eating disorder symptoms. In particular, associations between these constructs and the newly confirmed factor structure were compared with associations between these constructs and the original scoring method for the VASQ. Finally, as the original paper by Bifulco et al. (2003) and later studies (Carr et al., 2012; Doyle, McNamara, Cheevers, Finnegan, Logue \& McEntee, 2010) which used the VASQ did not examine sex differences, the current study also explored any differences that may be present between men and women when assessing adult attachment patterns using the VASQ. Although, Scohos and Bone (2012) did find that gender was associated with the Proximity-seeking subscale but not with the Insecurity subscale. Also, based on previous studies (Kobak \& Hazen, 1991; Roberts, Gotlib \& Kassel, 1996) using other adult attachment measures it is hypothesized that women will indicate more attachment insecurity compared to men.

In summary, it is plausible that the VASQ contains one, two, three or four factors. The aim of the present study is to confirm the factor structure of the VASQ, explore the relationship between the VASQ and other psychological constructs such as mood, stress and disordered eating behaviours, and examine sex differences using data gathered from a large predominantly community-based sample. 


\section{Method}

Participants and procedure

Participants were recruited as part of a longitudinal study investigating stress, mood, bodyweight and disordered eating $(N=1236)$. Participants were recruited from several sources including social networking sites and health and well-being forums and at the University of Hertfordshire. Participants completed the survey online which was created using the Bristol Online Survey (BOS; University of Bristol, 2010) facility. For the overall sample, mean age was 28.7 (s.d 10.7) and most participants were female, white, either employed or were students and either single or married/in a relationship (see Table 1).

\section{Measures}

\section{Primary Measure: Attachment}

The VASQ (Bifulco et al. 2003) is a 22-item scale assessing behaviors, emotions and attitudes relating to adult attachment. Participants are asked to rate each statement on a 5-point Likert scale ("Strongly disagree" to "Strongly agree"). The VASQ can be used to compute a total score reflecting vulnerable attachment and two separate subscales indicating insecure and proximity-seeking attachment patterns. Items 14 and 15 were positive items and so were reversed in order to be scored consistently with other vulnerable attachment items. Higher scores indicate a more vulnerable attachment when computing a total score and more insecurity and proximity-seeking attachment when using the subscales. Cronbach's alpha for the overall VASQ and its subscales, 
insecurity and proximity-seeking, in the current study were $\alpha=.79, \alpha=.82$ and $\alpha=.73$, respectively, which are similar to the Cronbach's alpha's reported for the insecurity $(\alpha=$ .82) and proximity-seeking ( $\alpha=.67)$ scales by Bifulco et al., (2003).

\section{$\underline{\text { Mood }}$}

Mood was assessed using the Short Depression-Happiness Scale (SDHS; Joseph, Linley, Harwood, Lewis \& McCollam, 2004). The SDHS (Joseph et al. 2004) consists of 6 statements, which requires participants to rate how they have felt over the last 7 days on a 4-point Likert scale ("Never" to "Often"). The SDHS (Joseph et al. 2004) is a bidirectional scale with lower scores indicating low mood and higher scores indicating happiness. Cronbach's alpha for the SDHS (Joseph et al. 2004) in the present sample was .88 .

\section{Disordered Eating Behaviors}

Disordered eating was assessed using the Eating Disorder Examination Questionnaire (EDE-Q; Fairburn \& Beglin, 1994). The EDE-Q (Fairburn \& Beglin, 1994) is a 36-item questionnaire consisting of 4 subscales assessing dietary restraint and weight, shape and eating concerns. Of the 36 items, 22 are rated on a 7-point Likert scale from "No days" to "Every day". From the remaining 14 items are diagnostic rather than continuous and were not included in the present analysis. Only the total EDE-Q score is reported here. Cronbach's alpha for the EDE-Q (Fairburn \& Beglin, 1994) in the current sample was $\alpha=$ .94 . 
$\underline{\text { Stress }}$

Stress was assessed using the Perceived Stress Scale-4 (PSS-4; Cohen \& Williamson, 1988), a 4-item measure of stress perceptions. Individuals were required to rate on a 5point Likert scale ("Very often" to "Never") the degree to which they appraise situations as stressful with higher scores indicating greater perceptions of stress. Cronbach's alpha for the PSS-4 (Cohen \& Williamson, 1988) in the present sample was .80.

\section{Statistical analysis}

The data were randomly split to perform Exploratory Factor Analysis (EFA) using the first half of the randomly split dataset (the training sample, $n=602$ ) in Mplus version 6 (Muthén \& Muthén, 2010). Oblique Geomin rotation was employed since the extracted factors were expected to correlate. A number of methods were used to determine the appropriate number of factors to extract. These were the Kaiser criterion (eigenvalues $>1$ ), scree plot, optimal co-ordinates, acceleration factor and comparison data method. This was undertaken in R using the nFactors package (Raiche \& Magis, 2011) and the comparison data method described by Ruscio and Roche (2012). Items were removed from the EFA if their factor loadings were non-significant or if they loaded significantly but weakly (i.e., <.40) onto more than one factor.

The best fitting models identified from the EFA (after removal of non-significant and double loadings) were subsequently selected for Confirmatory Factor Analysis (CFA) 
using the second half of the dataset (the testing sample, $n=634$ ) from which post-hoc modifications could be sought and evaluated.

CFA was conducted using Mplus version 6 (Muthén \& Muthén, 2010) with analyses computed using the Maximum Likelihood estimator $(\mathrm{ML})$ as responses were approximately normally distributed. Mplus (Muthén \& Muthén, 2010) generates several fit indices to assess how well the proposed model fits the sample data. Firstly, the $\mathrm{Chi}^{2}$ statistic may be used as a measure of fit between the sample covariance and fitted covariance matrices (Byrne, 1998). Although a non-significant $\mathrm{Chi}^{2}$ is desired, due to the large sample size of the current study, a significant $\mathrm{Chi}^{2}$ is expected based on standard statistical theory of how sample size, power and significance are associated (Cohen, 1992). Therefore, in addition to the $\mathrm{Chi}^{2}$ statistic several fit indices were evaluated including the Bayesian Information Criterion (BIC), Comparative Fit Index (CFI) and the Tucker Lewis Index (TLI). The model with the lowest BIC is preferred (Raftery, 1995) and values > .95 for the CFI and TLI indicate a reasonable fit (Hu \& Bentler, 1999). The Root Mean Square Error of the Approximation (RMSEA) is another fit index which takes into account the error of approximation in the population (Byrne, 1998). RMSEA values $<.05$ indicate a good model fit (Hu \& Bentler, 1999). Composite Reliability ( $\rho$ ) was used as a measure of internal reliability ( $\rho$ values $>.70$ indicate good internal reliability; Bacon, Sauer \& Young, 1995).

Similar to the original paper by Bifulco et al. (2003), further analyses were conducted to examine associations between the subscales of the VASQ and mood. Associations between the VASQ and disordered eating and stress were performed in order to 
validate the measure further. Additional analyses were also conducted to examine sex differences as a test of concurrent validity for each of the subscales. Effect sizes as measured by Cohen's $d$ were also reported with $.20, .50$ and .80 representing small, medium and large effects, respectively (Cohen, 1992).

\section{Results}

\section{Sample characteristics}

The data set of 1236 participants was randomly split into two training and testing samples from which EFA $(n=602)$ and CFA $(n=634)$ were conducted. Comparisons between the training and testing samples with regards to demographic variables are shown in Table 1 . The two groups did not differ with respect to age, $\mathrm{BMI}$, gender, ethnicity, marital and employment status. Furthermore, individual scores on the Proximity-seeking and Insecurity scales of the VASQ and the SDHS, EDE-Q and PSS-4 did not differ between the groups ( $p$ values range between .11 to 1.0). These results suggest that the random split was successful, allowing two independent samples to be analysed.

\section{Table 1 about here}

Exploratory Factor Analysis of the VASQ

Models extracting between 2 and 4 factors were considered based on the indication of the scree plot (elbows at 2 and 4 factors), acceleration factor (2 factors) optimal co-ordinates (4 factors), parallel analysis (4 factors) and comparison data 
method (4 factors). Six eigenvalues were observed to be greater than one, however the Kaiser criterion is known to over extract the number of factors (Fabrigar, 1999) and eigenvalues for the fifth and sixth factors were close to one so were not considered. The two factor EFA model revealed the expected insecurity and proximity-seeking structure, however the fit of the model was poor using standard SEM criteria $\left(X^{2}=946.5, d f=188\right.$, $p<.001 ; \mathrm{BIC}=37917.198, \mathrm{CFI}=.765, \mathrm{TLI}=.711, \mathrm{RMSEA}=.08)$. The three factor EFA model split the proximity-seeking scale into separate factors, but still exhibited poor model fit $\left(X^{2}=982.3, \mathrm{df}=168, \mathrm{p}<.001 ; \mathrm{BIC}=37781.035, \mathrm{CFI}=.840, \mathrm{TLI}=.781, \mathrm{RMSEA}=.07\right)$. The four factor model further split the insecure factor into two subscales $\left(X^{2}=513.3, d f=149\right.$, $\mathrm{p}<.001 ; \mathrm{BIC}=37733.595, \mathrm{CFI}=.887, \mathrm{TLI}=.825, \mathrm{RMSEA}=.06)$. The fit of the four factor model was still outside acceptable limits but was chosen for further analysis because it provided closer fit to the data than the two or three factor solutions, the pattern of loadings made theoretical sense and the extraction of four factors was indicated by both the parallel analysis and comparison data methods, which have been shown to perform well in simulation studies (Ruscio \& Roche, 2012).

Using the criteria outlined above, items 1 ("I take my time getting to know people"), 3 ("People let me down a lot"), 9 ("People close to me often get on my nerves") and 17 ("I feel uneasy when others confide in me") from the original Insecurity scale and items 4 ("I miss the company of others when I am alone"), 14 ("I look forward to spending time on my own") and 21 ("Its important to have people around me") from the Proximity-seeking scale were excluded. Based on the four-factor structure, items 3, 4, 17 and 21 were removed as their factor loadings were weak $(<.40)$ while items 1,9 
and 14 were eliminated due to both weak factor loadings $(<.40)$ and double loadings thus limiting their interpretation. The four-factor solution was re-estimated after excluding these items and the fit of the model was within acceptable limits $\left(X^{2}=98.1\right.$, $\mathrm{df}=51, \mathrm{p}<.001 ; \mathrm{BIC}=25951.783, \mathrm{CFI}=.978, \mathrm{TLI}=.955, \mathrm{RMSEA}=.04)$. The loading pattern was similar to the original solution described by Bifulco et al. (2003) but with the original Insecurity and Proximity-seeking scales each split into two further subscales and item 13 ("I am clingy with others") loading onto one of the insecurity subscales instead of a proximity-seeking subscale. Of the two subscales that spilt from the original proximityseeking subscale, one reflected overreliance and difficulty making decisions while the other reflected dependence and fear of abandonment. These were labelled lack of autonomy (common variance explained $=19.8 \%$ ) and anxious-dependent (common variance explained $=20.7 \%)$, respectively. Of the two subscales that split from the original insecure subscale, one reflected dismissiveness and mistrust, while the other reflected antagonism and clinginess. These were labelled avoidant-dismissive (common variance explained $=29.6 \%$ ) and ambivalent $($ common variance explained $=30.0 \%$, respectively. The rotated Geomin factor solution can be seen in table 2 .

\section{Table 2 about here}


Firstly, the original factor structure proposed by Bifulco et al. (2003) was examined in the testing sample and revealed poor fit to the data since all fit indices were outside their recommended cut-off ranges (see model A, Table 3).

\section{Table 3 about here}

Following the exclusion of several items (see above), the four-factor model derived from the EFA was evaluated in the testing sample using CFA. This model (model B) demonstrated a reasonable fit to the data as evidenced by the fit indices (see Table 3). However, there were issues regarding item 13, as in the EFA solution: item 13 loaded onto the Ambivalent factor but the modification indices (MI) ranged between 20.73 to 65.22 , suggesting this item should also load on the other three factors. Given the multiple loading of item 13 and, as the wording of this item seemed to be best described by the Ambivalent subscale, a further CFA was carried out removing item 13 completely (see model C, Table 3). The fit indices of this modified model were within acceptable levels (see model C, Table 3).

\section{Figure 1 about here}

While a four-factor solution has been found here, the original factor structure described by Bifulco et al. (2003) suggests that a two-factor solution, combining the two Proximityseeking subscales (Lack of autonomy and Anxious-dependent [6 items]) and the two 
Insecurity subscales (Avoidant-dismissive and Ambivalent [8 items]) identified here, might also be sufficient. This alternative higher-order model was tested and revealed a slight decline in all fit indices but still had a reasonable fit to the data, providing support for Bifulco et al.'s (2003) two-factor structure (see model D, Table 3), albeit with a smaller number of items $(n=14)$. The higher-order model is shown in figure 1 accompanied by standardised model coefficients.

Composite reliabilities $(\rho)$ for the four subscales of Lack of autonomy, Anxiousdependent, Avoidant-dismissive and Ambivalent in the modified VASQ were .69, .67, .79 and .64 , respectively. In addition, and similar to the original study by Bifulco et al. (2003), internal reliabilities were calculated for the shortened 14-item version of the VASQ by combining the Lack of autonomy and Anxious-dependent subscales to create the Proximity-seeking scale and the Avoidant-dismissive and Ambivalent to create the Insecurity scale. Composite reliabilities for the Proximity-seeking $(\rho=.55)$ and Insecurity $(\rho=.82)$ scales show that the Proximity-seeking scale is outside of the reasonable threshold $(\rho<.70$; Bacon et al., 1995).

VASQ: Intercorrelations with mood, disordered eating, stress and gender differences High intercorrelations were found between the subscales of the original 22-item and the new 14-item version of the VASQ. The Insecurity subscales taken from the two versions correlated at .97 $(p<.001)$ and the Proximity-seeking subscales correlated at .91 $(p<.001)$. Table 4 shows the intercorrelations between the VASQ subscales for the original 22-item version and the new shortened 14-item version of the VASQ. Significant 
correlations were found between the Insecurity and Proximity-seeking scales for both the original 22-item version and the new shortened 14 -item version of the VASQ. Significant correlations are present between the two Proximity-seeking subscales and the two Insecurity subscales for the 14-item VASQ and between the individual subscales except between the Lack of autonomy and Avoidant-dismissive subscales $(p=.81)$. As expected, smaller correlations are present between the subscales of the Insecurity scale and the subscales of the Proximity-seeking scale highlighting that these are distinct patterns of adult attachment.

\section{Table 4 about here}

Correlations between the SDHS, EDE-Q and PSS-4 and the Proximity-seeking and Insecurity scales of the VASQ were very similar for both the original 22-item and the new 14-item versions. High scores on the Proximity-seeking and Insecurity scale were associated with lower scores on the SDHS and higher scores on the EDE-Q and PSS-4. Significant correlations between the SDHS, EDE-Q and PSS-4 and the individual subscales of the 14-item version of the VASQ were found (Pearson $r$ 's ranging from -.47 to .41). Women scored higher on both the overall Proximity-seeking scale and its subscales (Lack of autonomy and Anxious-dependent) than men for the 14-item version of the VASQ but did not differ significantly for the Insecurity scale or its subscales. These differences are consistent with the results for the full 22-item VASQ (see Table 5). Cohen's $d$ was calculated as a measure of effect size which revealed small to large 
(Cohen, 1992) effect sizes, with medium effects for the proximity-seeking scale (and its subscales) and large effects for the EDE-Q.

\section{Table 5 about here}

\section{Discussion}

An EFA and CFA were conducted to determine the factor structure of the VASQ in a large and demographically diverse sample. To our knowledge the only study that has previously examined the factor structure of the VASQ is the original paper in which the measure was developed (Bifulco et al., 2003). Current findings indicate that the VASQ measures four factors, two types of proximity seeking, labelled Lack of autonomy and Anxious-dependent and two types of Insecurity of attachment, labelled Avoidantdismissive and Ambivalent. Lack of autonomy and Anxious-dependent differ as forms of proximity-seeking in that the former refers to relying on the attachment figure for help and support whereas the latter refers to anxiety over the attachment figure's absence. Avoidant-dismissive and Ambivalent differ as forms of Insecurity in that the former has a focus on one's internal emotional state in relation to others whereas the latter has a focus on the expectations of the individual and interactions with the attachment figure. This is similar to Bifulco et al.'s (2003) original findings but with the two attachment subscales each splitting into two further subscales. The analyses revealed that several modifications were required to achieve a good fit. These included the removal of several items due to low factor loadings and/or double loadings. The results also showed that a 
two-factor solution could be created by combining the two Proximity-seeking subscales (Lack of autonomy and Anxious-dependent) together and the two Insecurity subscales (Avoidant-dismissive and Ambivalent) together (should researchers prefer). Although combining the subscales together to create a two-factor solution does not show a detrimental effect on the psychometric quality of the VASQ, researchers should be cautious when combining these subscales as the Proximity-seeking scale of the 14-item solution was found to have low composite reliability which can present some challenges. A reason for low reliability found for the Proximity-seeking scale could be due to the small number of items that were retained following EFA and CFA. Elimination of several items during EFA and CFA can pose a threat to the validity of the measure. However, the original structure of the VASQ was maintained with both two- and fourfactor solutions producing the same two Insecurity and Proximity-seeking subscales in this sample providing further support for Bifulco et al.'s (2003) original model and also increasing its specificity. This is evidenced further by the fact that the effect size between the original and the modified VASQ scales with other psychological constructs are equivalent in size, thus suggesting that construct validity is maintained with the removal of eight items.

The original 22-item and the new 14-item versions performed almost identically in terms of intercorrelations between the Proximity-seeking and Insecurity scales (demonstrating high construct validity) and in their associations with mood, disordered eating, stress and sex. In terms of the more specified four-factor solution, while Bifulco et al. (2003) reported an association between depression and the Insecurity scale but 
not the Proximity-seeking scale, the present study found that mood was associated with both Insecurity and Proximity-seeking scales, although the correlations between the Insecurity scales and mood were larger compared to those between the Proximityseeking scales and mood. All scales and subscales were associated with disordered eating and perceptions of stress. Finally, sex differences were found for the overall Proximity-seeking scale for both the 14-item and 22-item versions of the VASQ and its subscales (Lack of autonomy and Anxious-dependent) with women reporting less autonomy and more dependence on others than men. Similarly, research using the VASQ has found that gender is associated with Proximity-seeking subscale but not with the Insecurity subscale (Sochos \& Bone, 2012). Studies using other measures of attachment styles have shown that men report feeling more comfortable with getting close to others than do women (Roberts et al., 1996) and married men report themselves to be less reliant on their wives (Kobak \& Hazen, 1991). In support of these findings, effect size analyses revealed that there is a medium effect of sex on proximityseeking behaviours. Also, in line with previous research, a very large effect of sex on disordered eating behaviours were found with women reporting more dysfunctional eating behaviours compared to men (e.g., Lewinsohn, Seeley, Moerk \& Striegel-Moore, 2002). Additionally, the associations between the VASQ and psychopathology and sex are maintained and further highlight the predictive validity of the VASQ when using a psychometrically improved version identified through CFA. 
The current study recruited a non-clinical sample and responses from a clinical group may have revealed a different factor solution. Another possible limitation is that the data were collected online and it is arguable that the use of traditional paper-andpencil methods of data collection may have led to a different set of results. However, previous research has demonstrated that online responses are generally as valid and reliable as those collected offline (Hiskey, 2002).

The present study has noteworthy strengths, for example the recruitment of a large predominantly community-based sample. This not only provided the analyses with good power but also allows the findings to be generalised to groups outside of the sample of middle-aged women and their family members with which the VASQ was originally developed. Nevertheless, the sample in the present study was predominantly white and female and therefore was not entirely representative of the general population. A caveat of these findings is that further testing should be conducted before this measure is used in older adults, as the mean age of the present sample was 29 years old. In addition, associations with mood, disordered eating and stress were cross-sectional rather than longitudinal, in contrast to the association between onset of depression and the VASQ in Bifulco et al.'s (2003) study. Finally, as very few items were found to load onto the Proximity-seeking scale and its subscales, the overall reliability of this component of the measure was compromised.

\section{Implications}


Notwithstanding the above limitations, our findings have a number of important implications. From a theoretical point of view, the present study supported the original findings of Bilfulco et al. (2003), indicating that a two-factor structure consisting of insecurity of attachment and proximity-seeking patterns provides a suitable fit. Furthermore, the discovery that the two original scales can be split into two further subscales in order to differentiate between avoidant-dismissive and ambivalent types of insecure attachment and lack of autonomy versus anxious-dependent types of proximity-seeking attachment patterns is potentially important. Although measures of attachment in adulthood label attachment patterns differently, there are similarities between measures such as the number of attachment patterns that are found and the items that reflect each style. Therefore, the finding that the two original VASQ scales split into two further subscales each is similar to other (and more widely used) adult attachment measures (e.g., Bartholomew \& Horowitz, 1991; Brennan et al., 1998; Collins \& Read, 1990; Hazan \& Shaver, 1987). Similarities between the four attachment patterns derived from the VASQ are also similar to those described by other measures of adult attachment. For example, the anxious-dependent component of proximityseeking reflects a combination of the items that reflect the anxious and depend categories by Collins and Read (1990) and anxiety items from the ECR (Brennan et al., 1998). The avoidant-dismissive component of the insecurity of attachment scale contains items that are similar to the dismissive-avoidant category reflected in the RQ (Bartholomew \& Horowitz, 1991). 
Furthermore, the use of both two- and four-factor models of the VASQ will allow future research to build on our current understanding of these attachment patterns and how these separable attachment styles can impact differently on outcomes and/or respond differently to intervention. These four attachment patterns are clearly separable aspects of adult attachment styles but the degree to which this distinction is clinically and/or theoretically meaningful requires further investigation. The demonstration of reliability and validity of the VASQ supports its future use by both researchers and clinicians to evaluate those who are at high risk for psychopathology such as depression, anxiety, stress and eating disorders.

Future research should explore the associations between the VASQ and other measures of attachment. For example, the Avoidant-dismissive versus Ambivalent subtypes of Insecure attachment found here may be related to the model-of-self versus model-ofother scales that can be calculated in the RQ (Bartholomew \& Horowitz, 1991). Whether the modified VASQ reported here outperforms other attachment measures in predicting psychopathology (as was found in Bifulco et al.'s (2003) study) also requires confirmation.

The current study has built on the original development of the VASQ. Specifically, it has expanded its generalisability by using a large, predominantly community-based sample. However, in order to develop the VASQ further, emphasis must be placed on using this potentially valuable tool in other settings in order to demonstrate its generalisability to a range of diverse clinical and non-clinical groups and provide further support for its two- and four-factor structure. 


\section{References}

Ainsworth, M. D. S. (1985). Attachments across the life span. Bulletin of the New York Academy of Medicine, 61, 792-811

Ainsworth, M. D. S., Blehar, M. C., Waters, E. \& Wall, S. (1978). Patterns of attachment:

A psychological study of the strange situation. Hillsdale, NJ: Erlbaum

Bacon, D. R., Sauer, P. L. \& Young, M. (1995). Composite reliability in Structural

Equations Modeling. Educational and Psychological Measurement, 55, 394-406

Bartholomew, K. \& Horowitz, L. M. (1991). Attachment styles among young adults: A

test of a four-category model. Journal of Personality and Social Psychology, 61, 226-244

Bowlby, J. (1977). The making and breaking of affectional bonds: I. Aetiology and

Psychopathology in the light of attachment theory. British Journal of Psychiatry, 130,

201-210

Bifulco, A., Kwon, J. H., Jacobs, C., Moran, P. M., Bunn, A. \& Beer, N. (2006). Adult attachment style as mediator between childhood neglect/abuse and adult depression and anxiety. Social Psychiatry and Psychiatric Epidemiology, 41, 796-805

Bifulco, A., Mahon, J., Kwon, J. H., Moran, P. M. \& Jacobs, C. (2003). The Vulnerable Attachment Style Questionnaire (VASQ): An interview-based measure of attachment styles that predict depressive disorder. Psychological Medicine, 33, 1099-1110

Bifulco, A., Moran, P. M., Ball, C. \& Bernazzani, O. (2002a). Adult attachment style: I. Its relationship to clinical depression. Social Psychiatry and Psychiatric Epidemiology, 37, 50-59 
Bifulco, A., Moran, P. M., Ball, C. \& Lillie, A. (2002b). Adult attachment style: II. Its relationship to psychosocial depressive-vulnerability. Social Psychiatry and Psychiatric Epidemiology, 37, 60-67

Brennan, K. A., Clark, C. L. \& Shaver, P. R. (1998). Self-report measurement of adult attachment: An integrative overview. In J. A. Simpson \& W. S. Rholes (Eds.), Attachment theory and close relationships (pp. 46-76). New York: Guildford Press Bristol Online Survey (BOS, 2010). University of Bristol. http://www.survey.bris.ac.uk Byrne, B. M. (1998). Structural equation modelling with Lisrel, Prelis, and Simplis: Basic concepts, applications, and programming. Mahwah, NJ: Lawrence Erlbaum Associates, Inc.

Carr, S., Colthurst, K., Coyle, M. \& Elliott, D. (2012). Attachment dimensions as predictors of mental health and psychosocial well-being in the transition to the University. European Journal of Psychology in Education Cohen, J. (1992). Power primer. Psychological Bulletin, 112, 155-159 Cohen, S. \& Williamson, G. (1988). Perceived stress in a probability sample of the United States. In Spacapam, S. and Oskamp, S. (Eds.) The Social Psychology of Health: Claremont Symposium on Applied Social Psychology. Newbury Park, CA: Sage Collins, N. L. \& Read, S. J. (1990). Adult attachment, working models, and relationship quality in dating couples. Journal of Personality and Social Psychology, 58, 644-663 Crowell, J. A. \& Treboux, D. (1995). A review of adult attachment measures: Implications for theory and research. Social Development, 4, 294-327 
Ditzen, B., Schmidt, S., Strauss, B., Nater, U. M., Ehlert, U. \& Heinrichs, M. (2008). Adult attachment and social support interact to reduce psychological but not cortisol responses to stress. Journal of Psychosomatic Research, 64, 479-486

Doyle, O., McNamara, K., Cheevers, C., Finnegan, S., Logue, C. \& McEntee, L. (2010). Preparing for life early childhood intervention impact evaluation report 1: Recruitment and baseline characteristics. Discussion Paper Series, No. 201050, Geary Institute: University College Dublin Fabrigar, L. R., Wegener, D. T., MacCallum, R. C., \& Strahan, E. J. (1999). Evaluating the use of exploratory factor analysis in psychological research. Psychological Methods, 4(3), $272-299$

Fairburn, C. G. \& Beglin, S. J. (1994). Assessment of eating disorders: Interview or selfreport questionnaire. International Journal of Eating Disorders, 16, 363-370. Hazan, C. \& Shaver, P. (1987). Romantic love conceptualized as an attachment process. Journal of Personality and Social Psychology, 52, 511-524

Hiskey, S. (2002). Intrusive experiences and psychological adjustment following trauma. Unpublished doctoral dissertation, University of Essex, Essex, United Kingdom Hu, L. \& Bentler, P. M. (1999). Cutoff criteria for fit indexes in covariance structure analysis: Conventional criteria versus new alternatives. Structural Equation Modeling, 6, 1-55

Joseph, S., Linley, S. J., Harwood, J., Lewis, C. A., \& McCollam, P. (2004). Rapid assessment well-being: The Short Depression-Happiness Scale (SDHS). Psychology and Psychotherapy: Theory, Research and Practice, 77, 463-478

Kidd, T., Hamer, M. \& Steptoe, A. (2011). Examining the association between adult 
attachment style and cortisol responses to acute stress. Psychoneuroendocrinology, 36, 771-779

Kobak, R. R. \& Hazan, C. (1991). Attachment in marriage: Effects of security and accuracy of working models. Journal of Personality and Social Psychology, 60, 861-869

Lewinsohn, P. M., Seeley, J. R., Moerk, K. C. \& Striegel-Moore, R. H. (2002). Gender differences in eating disorder symptoms in young adults. International Journal of Eating Disorders, 32(4), 426-440

Lyddon, W. J., Bradford, E. \& Nelson, J. P. (1993). Assessing adolescent and adult attachment: A review of current self-report measures. Journal of Counselling and Development, 71, 390-395

Mickelson, K. D., Kessler, R. C. \& Shaver, P. R. (1997). Adult attachment in a nationally representative sample. Journal of Personality and Social Psychology, 73, 1092-1106 Muthén, L. K. \& Muthén, B. O. (2010). Mplus Version 6. Los Angeles, CA: Muthén \& Muthén

Raftery, A. E. (1995). Bayesian model selection in Social Research. Sociological Methodology, 25, 111-163

Raiche, G., \& Magis, D. (2011). R package nFactors (version 2.3.3): Parallel Analysis and Non Graphical Solutions to the Cattell Scree Test. Retrieved from http://CRAN.Rproject.org/package $=$ nFactors

Ravitz, P., Maunder, R., Hunter, J., Sthankiya, B. \& Lancee, W. (2010). Adult attachment measures: A 25-year review. Journal of Psychosomatic Research, 69, 419-432 
Roberts, J. E., Gotlib, I. H. \& Kassel, J. D. (1996). Adult attachment security and symptoms of depression: The mediating roles of dysfunctional attitudes and low selfesteem. Journal of Personality and Social Psychology, 70, 310-320

Ruscio, J., \& Roche, B. (2012). Determining the number of factors to retain in an exploratory factor analysis using comparison data of known factorial structure. Psychological Assessment, 24(2), 282-292

Scohos, A. \& Bone, A. (2012). Attitudes towards continuing bonds, attachment vulnerability, and the moderating effects of gender. Journal of Loss and Trauma, 17, $260-270$

Sloman, L., Gilbert, P. \& Hasey, G. (2003). Evolved mechanisms in depression: The role and interaction of attachment and social rank in depression. Journal of Affective Disorders, $74,107-121$

Ward, A., Ramsay, R. \& Treasure, J. (2000). Attachment research in eating disorders. British Journal of Medical Psychology, 73, 35-51

Zachrisson, H. D. \& Skårderud, F. (2010). Feelings of insecurity: Review of attachment and eating disorders. European Eating Disorders Review, 18, 97-106 
Table 1: Demographic variables across EFA and CFA split sample

\begin{tabular}{|c|c|c|c|}
\hline Variable & $\begin{array}{c}\text { Total } \\
(n=1236)\end{array}$ & $\begin{array}{c}\text { EFA Sample } \\
(n=602)\end{array}$ & $\begin{array}{c}\text { CFA Sample } \\
(n=634)\end{array}$ \\
\hline Age (SD) & $28.7(10.7)$ & $28.7(10.8)$ & $28.7(10.7)$ \\
\hline Male \% (n) & $20.2(250)$ & $19.1(115)$ & $21.3(135)$ \\
\hline Female \% (n) & $79.8(986)$ & $80.9(487)$ & 78.7 (499) \\
\hline \multicolumn{4}{|l|}{ Ethnicity (n) } \\
\hline White \% & $75.4(932)$ & $75.4(454)$ & $75.4(478)$ \\
\hline Other \% & $24.6(304)$ & $24.6(148)$ & $24.6(156)$ \\
\hline \multicolumn{4}{|l|}{ Marital status \% (n) } \\
\hline Single & $39.0(482)$ & $38.7(233)$ & $39.3(249)$ \\
\hline Married & $21.1(261)$ & $21.9(132)$ & $20.3(129)$ \\
\hline In a relationship & $22.6(279)$ & $22.4(135)$ & $22.7(144)$ \\
\hline Living with a partner & $13.5(167)$ & $13.1(79)$ & $13.9(88)$ \\
\hline Divorced & $3.3(41)$ & $3.5(21)$ & $3.2(20)$ \\
\hline Widowed & $.5(6)$ & $.3(2)$ & $.6(4)$ \\
\hline \multicolumn{4}{|l|}{ Employment \% (n) } \\
\hline Student & $50.3(622)$ & $50.8(306)$ & $49.8(316)$ \\
\hline Employed & $41.3(510)$ & $40.5(244)$ & $42.0(266)$ \\
\hline Unemployed & $4.9(60)$ & $5.5(33)$ & $4.3(27)$ \\
\hline At home with children & $2.5(31)$ & $2.5(15)$ & $2.5(16)$ \\
\hline Retired & $1.1(13)$ & $.7(4)$ & $1.4(9)$ \\
\hline BMI (SD) & $24.9(6.2)$ & $25.0(6.0)$ & $24.8(6.3)$ \\
\hline SDHS (SD) & $11.8(4.2)$ & $12.0(4.2)$ & $11.6(4.2)$ \\
\hline EDE-Q (SD) & $2.0(1.4)$ & $2.0(1.5)$ & $1.9(1.4)$ \\
\hline PSS-4 (SD) & $7.2(3.4)$ & $7.1(3.3)$ & $7.2(3.5)$ \\
\hline \multicolumn{4}{|l|}{ 22-item VASQ } \\
\hline Insecurity $(S D)$ & $31.9(7.6)$ & $31.8(7.4)$ & $31.9(7.7)$ \\
\hline Proximity-seeking $(S D)$ & $29.0(5.9)$ & $29.0(6.0)$ & $29.0(5.9)$ \\
\hline
\end{tabular}

Note. SDHS = Short Depression-Happiness Scale; EDE-Q = Eating Disorder Examination Questionnaire; PSS-4 = Perceived Stress Scale-4 
Table 2: EFA solution of the VASQ

\section{Factor}

No. Item

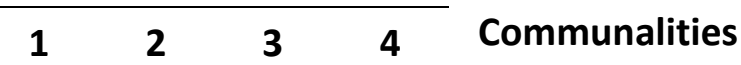

2 I rely on others to help me make decisions

$\begin{array}{lllll}.83 & .01 & .14 & .24 & .50\end{array}$

7 I usually rely on advice from others when I've got a

$\begin{array}{lllll}.67 & -.09 & .29 & .20 & .50\end{array}$

problem

15 I like making decisions on my own*

5 It's best not to get too emotionally close to other people

8 I feel uncomfortable when people get too close to me

18 I find it hard to trust others

19 Having people around me can be a nuisance

22 I find it difficult to confide in people

6 I worry a lot if people I live with arrive back later than expected

$\begin{array}{lllll}.54 & -.10 & .13 & .17 & .25 \\ .002 & .63 & .12 & .35 & .38 \\ .01 & .75 & .14 & .29 & .41 \\ -.09 & .65 & .19 & .37 & .65 \\ -.11 & .51 & .09 & .40 & .24 \\ -.10 & .63 & .08 & .23 & .49 \\ .14 & .10 & .67 & .22 & .37\end{array}$

.25

.38

.41

.65

.24

$\begin{array}{llll}.04 & .15 & .57 & .22\end{array}$

.31

$\begin{array}{lllll}.19 & .19 & .68 & .49 & .60\end{array}$

$\begin{array}{lllll}.19 & .43 & .26 & .69 & .61\end{array}$

$\begin{array}{lllll}.11 & .24 & .23 & .55 & .25\end{array}$

$\begin{array}{lllll}.29 & .06 & .38 & .57 & .22\end{array}$

$\begin{array}{lllll}.07 & .33 & .16 & .62 & .28\end{array}$

20 I feel people haven't done enough for me

$\begin{array}{llll}3.84 & 2.31 & 1.43 & 1.16\end{array}$

Eigen value

Note. * Item 15 was reverse coded; †Item 13 was excluded during CFA; Items loading onto the relevant factor are indicated in bold; Factor labels are: 1 = Lack of autonomy; 2 = Avoidant-dismissive; 3 = Anxious-dependent; 4 = Ambivalent 
Table 3: Summary of the CFA results for the several VASQ models and fit indices

\begin{tabular}{|c|c|c|c|c|c|c|c|c|c|}
\hline Model & & $\mathrm{Chi}^{2}$ & $\begin{array}{l}\text { No of free } \\
\text { Parameters }\end{array}$ & df & $p$-value & BIC & CFI & TLI & RMSEA \\
\hline A & Original VASQ & 1407.2 & 67 & 208 & $<.001$ & 39895.112 & .675 & .639 & .095 \\
\hline B & VASQ from EFA & 303.6 & 51 & 84 & $<.001$ & 27191.946 & .905 & .881 & .064 \\
\hline C & $\begin{array}{l}\text { Modified model } \\
\text { (Item } 13 \text { removed) }\end{array}$ & 186.7 & 48 & 71 & $<.001$ & 25376.599 & .945 & .929 & .051 \\
\hline D & $\begin{array}{l}\text { Higher-order } \\
\text { model }\end{array}$ & 212.0 & 45 & 74 & $<.001$ & 25382.604 & .934 & .919 & .054 \\
\hline
\end{tabular}


Table 4: Intercorrelations between the VASQ subscales and psychopathology scores ( $N=$ 1236)

\section{Item VASQ}

Insecurity Proximity- SDHS EDE-Q
seeking

$\begin{array}{lllll}\text { Proximity-seeking } & .16^{* *} & & & \\ \text { SDHS } & -.54^{* *} & -.19 * * & & \\ \text { EDE-Q } & .33^{* *} & .18^{* *} & -.46^{* *} & \\ \text { PSS-4 } & .45^{* *} & .31 * * & -.71^{* *} & .39 * *\end{array}$

\section{Item VASQ}

\begin{tabular}{|c|c|c|c|c|c|}
\hline Insecurity & $\begin{array}{c}\text { Proximity- } \\
\text { seeking }\end{array}$ & $\begin{array}{l}\text { Avoidant- } \\
\text { dismissive }\end{array}$ & Ambivalent & $\begin{array}{c}\text { Lack of } \\
\text { autonomy }\end{array}$ & $\begin{array}{l}\text { Anxious- } \\
\text { dependent }\end{array}$ \\
\hline
\end{tabular}

\begin{tabular}{|c|c|c|c|c|c|c|}
\hline Proximity-seeking & $.22^{* *}$ & & & & & \\
\hline Avoidant-dismissive & $.93 * *$ & $.14^{* *}$ & & & & \\
\hline Ambivalent & $.77 * *$ & $.28 * *$ & $.47^{* *}$ & & & \\
\hline Lack of autonomy & .05 & $.76 * *$ & -.01 & $.13^{* *}$ & & \\
\hline Anxious-dependent & $.29 * *$ & $.80 * *$ & $.22 * *$ & $.30 * *$ & $.21 * *$ & \\
\hline SDHS & $-.54 * *$ & $-.22 * *$ & $-.46 * *$ & $-.47^{* *}$ & $-.15^{* *}$ & $-.18^{* *}$ \\
\hline EDE-Q & $.34 * *$ & $.21^{* *}$ & $.30 * *$ & $.27^{* *}$ & $.14^{* *}$ & $.19 * *$ \\
\hline PSS-4 & $.44 * *$ & $.33^{* *}$ & $.37 * *$ & $.41 * *$ & $.24^{* *}$ & $.27^{* *}$ \\
\hline
\end{tabular}

Note. ${ }^{* *} p<.001 ;$ SDHS $=$ Short Depression-Happiness Scale; EDE-Q = Eating Disorder Examination Questionnaire; PSS-4 = Perceived Stress Scale-4 
Table 5: Means (Standard Deviation in brackets) for participant's age, BMI, SDHS, EDE-Q, PSS-4 and VASQ scores for the 22- and 14-item versions as a function of $\operatorname{sex}(N=1236)$

\begin{tabular}{|c|c|c|c|c|}
\hline Variable & $\begin{array}{c}\text { Men } \\
(N=250)\end{array}$ & $\begin{array}{l}\text { Women } \\
(N=986)\end{array}$ & Significance & Cohen's d \\
\hline Age & $29.6(11.3)$ & $28.5(10.6)$ & $t(1222)=1.46, p=.15$ & .08 \\
\hline BMI & $25.4(5.6)$ & $24.8(6.3)$ & $t(417.45)=1.67, p=.10$ & .16 \\
\hline SDHS & $12.4(4.2)$ & $11.6(4.2)$ & $t(1234)=2.66, p=.01$ & .15 \\
\hline EDE-Q & $1.3(1.2)$ & $2.1(1.4)$ & $t(469.89)=-9.26, p<.001$ & -.85 \\
\hline PSS-4 & $6.5(3.5)$ & $7.3(3.3)$ & $t(1234)=-3.37, p=.001$ & -.19 \\
\hline \multicolumn{5}{|l|}{ Original 22-item VASQ } \\
\hline Insecurity & $31.4(7.5)$ & $32.0(7.6)$ & $t(1234)=-.98, p=.33$ & -.06 \\
\hline Proximity-seeking & $27.1(5.9)$ & $29.5(5.8)$ & $t(1234)=-5.91, p<.001$ & -.34 \\
\hline \multicolumn{5}{|l|}{ New 14-item VASQ } \\
\hline \multicolumn{5}{|l|}{ Two-factor solution } \\
\hline Insecurity & $20.2(5.7)$ & $20.4(5.8)$ & $t(1234)=-.59, p=.56$ & -.03 \\
\hline Proximity-seeking & $16.0(4.0)$ & $18.0(4.0)$ & $t(1234)=-7.01, p<.001$ & -.40 \\
\hline \multicolumn{5}{|l|}{ Four-factor solution } \\
\hline \multicolumn{5}{|l|}{ Insecurity } \\
\hline Ambivalent & $6.7(2.5)$ & $6.6(2.5)$ & $t(1234)=.33, p=.75$ & .02 \\
\hline Avoidant-dismissive & $13.5(4.2)$ & $13.8(4.2)$ & $t(1234)=-1.01, p=.32$ & -.06 \\
\hline \multicolumn{5}{|l|}{ Proximity-seeking } \\
\hline Lack of autonomy & $7.5(2.4)$ & $8.5(2.5)$ & $t(1234)=-5.56, p<.001$ & -.32 \\
\hline Anxious-dependent & $8.5(2.5)$ & $9.5(2.7)$ & $t(1234)=-5.30, p<.001$ & -.30 \\
\hline
\end{tabular}

Note. SDHS = Short Depression-Happiness Scale; EDE-Q = Eating Disorder Examination Questionnaire; PSS-4 = Perceived Stress Scale 


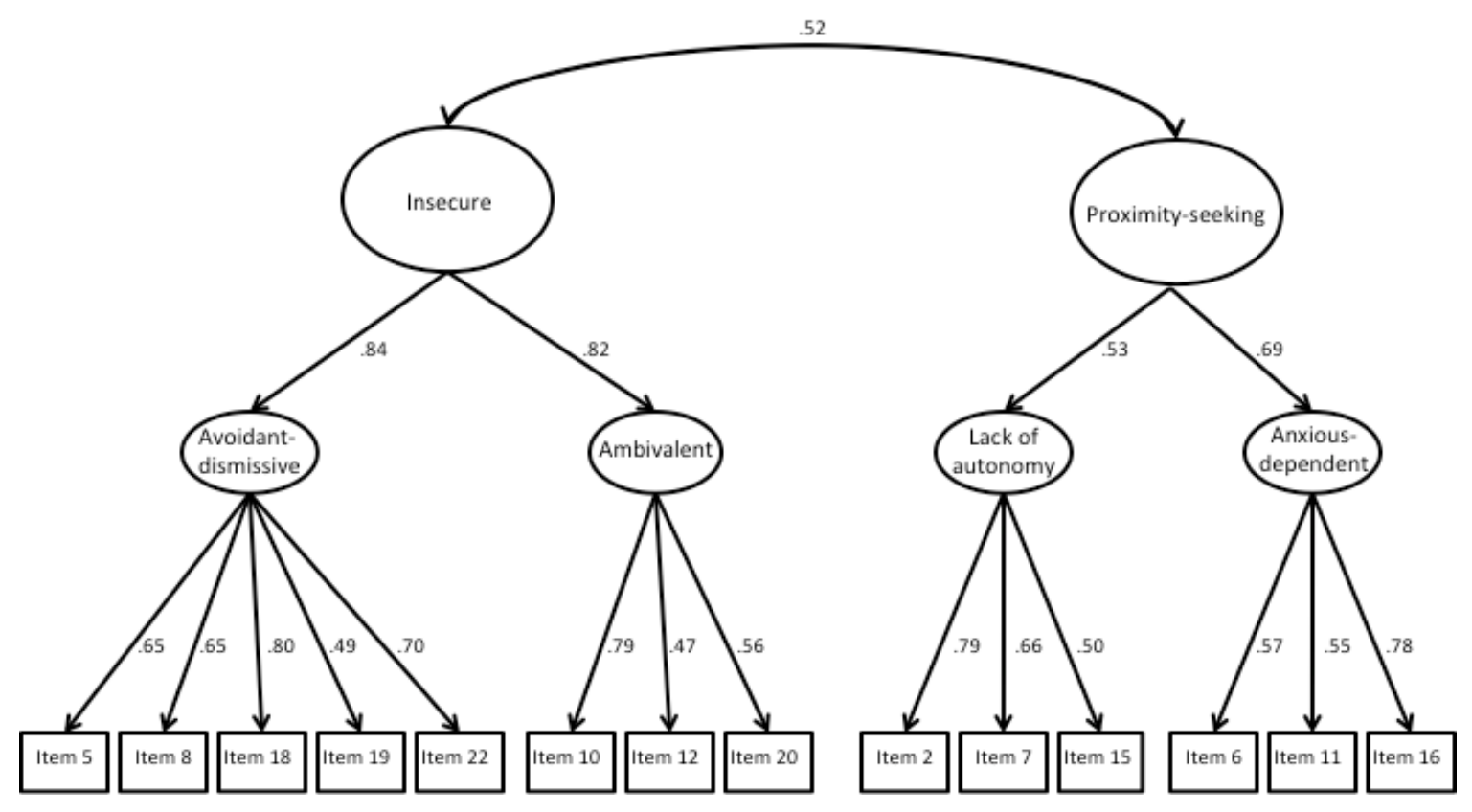

Figure 1: CFA: Higher-order VASQ model

Note. All standardised coefficients are significant at $p<.001$ 